\title{
DESIGN OF TWO STAGE PLANETARY GEAR TRAIN FOR HIGH REDUCTION RATIO
}

\author{
Prabhakar Vitthal Pawar', P.R. Kulkarni \\ ${ }^{1}$ M.E. (Design ), Mechanical Engineering, Walchand Institute of Technology, Solapur-413003, Maharashtra, India \\ ${ }^{2}$ Professor, Mechanical Engineering, Walchand Institute of Technology, Solapur-413003, Maharashtra, India
}

\begin{abstract}
Planetary Gear Trains are extensively used for the power transmission and are the most critical component. Planetary gearboxes are used frequently to match the inertias, lower the motor speed, boost the torque, and at the same time provide a sturdy mechanical interface for pulleys, cams, drums and other mechanical components. This paper presents the advantages of planetary gear systems over other, consideration to be given while determining the reduction ratios of gear box, minimum and maximum reductions per stage of planetary gear pairs. Also the case study to determine the reduction ratio of two stage gear box is discussed. The comparison of planetary gear system over helical gears systems is done on the basis of volume, weight and torque density
\end{abstract}

Keywords: Planetary Gears, Gear train, IS 4460, Torque density. ***.

\section{INTRODUCTION}

Planetary gear systems normally consist of a centrally pivoted sun gear, a ring gear, and several planet gears found between the sun gear and ring gear. Now, industrial applications demands high torque in compact (a high torque/volume) and light (a high torque/weight ratio) package. In planetary gears, torque density can be increased by adding more planets through multiple gear mesh points. This means a planetary gear with say three planets can transfer three times the torque of a similar sized fixed axis "standard" spur gear system as shown in Figure 1.

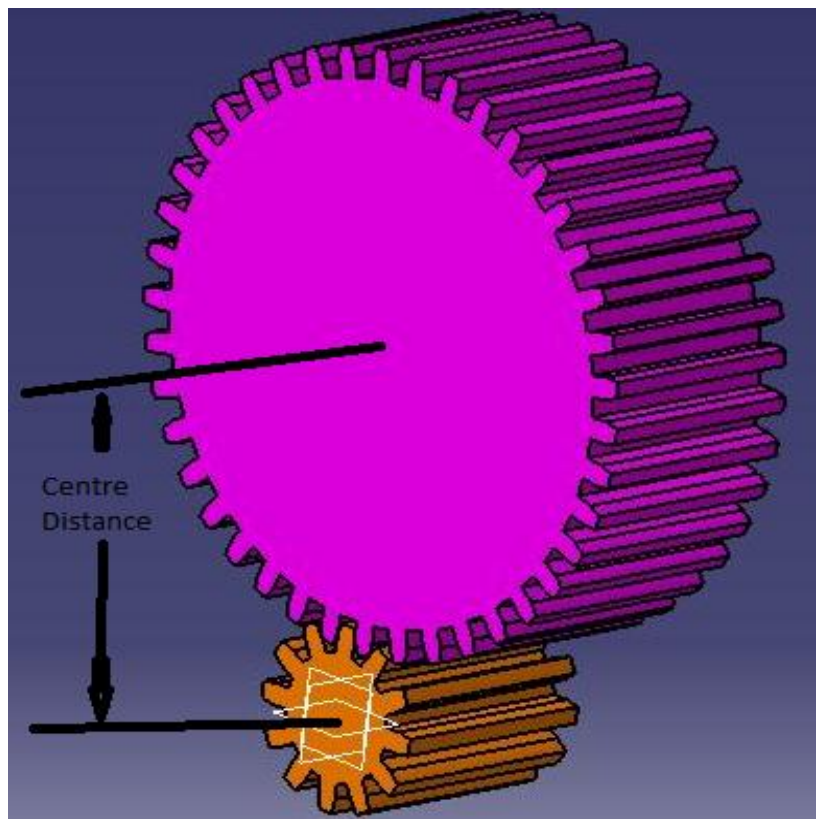

Fig-1: Fixed axis "standard" gear

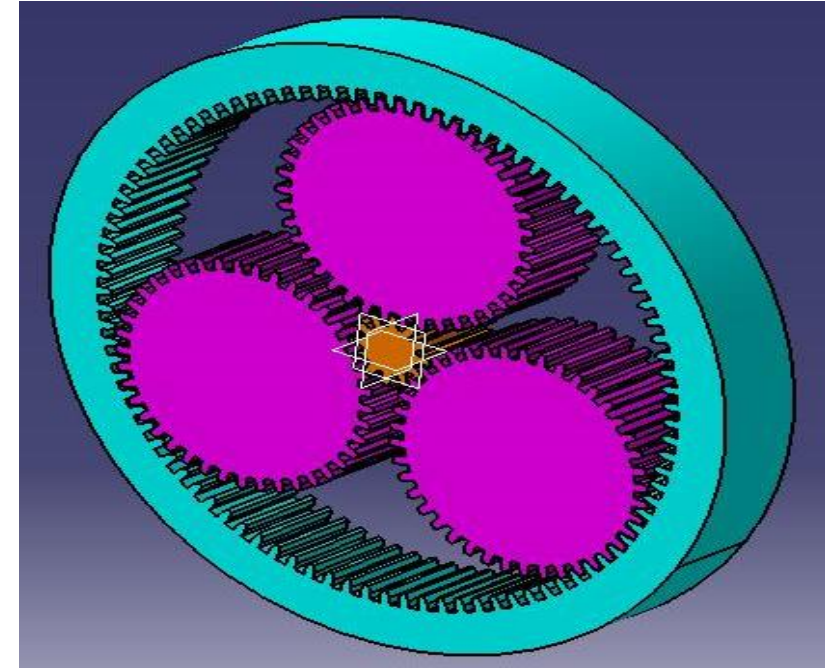

Fig-2: Planetary "Epicyclical” gear system

The applied load to planetary gears are distributed onto multiple gear mesh points means the load is supported by $N$ contacts (where $N=$ number of planet gears) increasing the torsional stiffness of the gear train by factor $N$. Hence it lowers the lost motion compared to similar size standard gear trains. High rotational stiffness is important for applications with positioning accuracy and repeatability requirements; especially under fluctuating loading conditions. Hence planetary gears are used for such applications in automation. Added inertia results in an additional torque/energy requirement for both acceleration and deceleration. The smaller gears in planetary system result in lower inertia. Compared to a same torque rating standard gearbox, it is a fair approximation to say that the planetary gearbox inertia is smaller by the square of the number of planets. Again, this advantage is rooted in the distribution or "branching" of the load into multiple gears meshes locations. 
Fixed axis spur gears will exhibit lubrication "starvation" and quickly fail if running at high speeds because the lubricant is slung away. Hence pressurized forced lubrication systems are required for better lubrication. On the other hand, grease lubrication is impractical because of a it's "tunneling effect," in which the grease, over time, is pushed away and cannot flow back into the mesh. In planetary systems the lubricant cannot escape- it is continuously redistributed, "pushed and pulled" or "mixed" into the gear contacts, ensuring safe lubrication practically in any mounting position and at any speed. Hence planetary gearboxes can be grease lubricated for the life[12]. This feature is inherent in planetary gearing because of the relative motion between the different gears making up the arrangement.

In short the planetary gears systems have high torque density, compact, low inertia and can be grease lubricated for life, which are demands of industrial applications. Hence the author has taken the work on design of compact planetary gear train used in gear boxes used for automation in car parking systems. Next paragraph explains the literature review on the planetary gear design and analysis.

\section{LITERATURE REVIEW}

A literature review on planetary gear train design and analysis was carried out and a brief report of the same is presented as below:

Lehao Chang et.al.[1] presented study on robust model for determining the mesh stiffness of cylindrical gears. The deformation of gear tooth was separated into a global term and a local contact term, which combines the advantages of both finite element method and analytical contact theory. As the application of substructure method and even mesh technique, the proposed method has higher computational efficiency and improved consistency compared with conventional FE models using contact elements. The gear body parameters have great influence on the mesh stiffness. The decreased rim thickness and web thickness will result in smaller mesh stiffness. In addition, the size of central hole will also lead to evident change for mesh stiffness. The contact ratio of the gear pair changes with change in the helix angle, face width, pressure angle and addendum coefficient, and that is the same for the fluctuation of mesh stiffness as well as the vibration of the system. Dr. Alexander Kapelevich [2] reported analysis and design of differential epicyclical gear arrangements that provide extremely high gear ratios. But this was suitable for low torque application like positioning in robotics. Ovidiu Bunga et. al.[3] in their study on optimal mass minimization design of two stage coaxial speed reducer with Genetic Algorithm compared the traditional design of speed reducer with optimal design by GA. The study about the trade-off between the mass and the service life was presented \& they concluded that the required service life has to be sacrificed with $75 \%$ for a $2.5 \mathrm{~kg}$ saving (roughly $7 \%$ ). Bernad et. al.[4] presented a study on light weight design of planetary gears transmission. Higher number of applied planet gears results in a higher mesh load factor, as well as an increasing difficulty in assembling the planets with low numbers of teeth. Thus the number of teeth for the central gears was increased in order to compensate for the advantage of a better power division for higher numbers of applied planets. Difference in the centre distances of two gear pairs was offset by applying addendum modifications for transmission concepts with high gear ratios. In that case the addendum modifications cannot be applied in the best way to reduce the tooth-load factors, or to increase efficiency. One possibility in order to achieve equal centre distances would be to use different normal modules for each transmission stage. Syed Ibrahim Dilawer et. al.[5] presented study on optimal design of the gear train with the load analysis carried out in the gear trains by varying the module $(3,4,5$, 6 ) for all the gears for three different power levels $10 \mathrm{HP}, 15$ $\mathrm{HP}$ and 20HP. Cheon-Jae Bahk et al. [6] presented a nonlinear dynamic model of a planetary gear with tooth profile modification (TPM). The minimal dynamic response was achieved at different combination of sun-planet and ring-planet mesh TPM. Different TPMs are required for minimizing gear vibration depending on the amount of mesh stiffness fluctuation and the mesh phase. Different TPM minimizes the vibration at different vibration modes. Nenad Marjanovic et. al.[7] in their study of practical approach to the optimization of gear trains with spur gears presented selection of optimal gear trains and selection of optimal position for shaft axes of gears trains with spur gears. The volume of the gear train with spur gears is reduced by $22.5 \%$. Software GTO provides the required results in a very short time. Jelena Stefanović et. al.[8] presented method of optimization of planetary gears by formulation of objective functions taking optimization variables as no. of teeth, no of planets, gear modules, face width and objective function as mass, Volume, efficiency, manufacturing costs. Ulrich Kissling et.al.[9] presented a study on optimization Procedure for Complete Planetary Gearboxes with Torque, Weight, Costs and Dimensional Restrictions. PlanetaryVariant-Generator permits an arbitrary number of completely defined planetary gearbox variants to be created automatically using functions for the layout of gear-stages, shaft dimensions, bearings and planet carrier; given the required torque capacity, life requirement, safety factors and the total ratio. As specified by the user, gearbox variants with different number of stages and different distribution of the ratios over the stages are calculated. The weight reduction was higher than expected, going up to $30 \%$. Manufacturing price reduction was even higher, going up to $50 \%$. B. Venkatesh et. all [10] in their study of design, modeling \& manufacturing of helical gear carried a iterative study to design the gear by AGMA \& verified the results with ANSYS for the gear used in marine application with variation in material. Dr. Ing. T. Schulze et. al.[11] Presented report on load distribution in planetary gears using MDESIGN software. The uniform load distribution on gear flank gives better life. The Mdesign software gives complete product information in the early phase of product life cycle (PLC). G.G. Antony[12] in study on precision planetary gear-heads presented advantages of planetary gear-heads using with servo motors.

Finding on the review of literature in planetary gear design and analysis are summarized in next point. 


\subsection{Findings of Literature Review:}

From the above study on literature review of design and analysis of planetary gears following are few important points to be noted:

a) The extensive research in the field of planetary gear design has already been done.

b) Many researchers reported study on single stage planetary gears arrangement.

c) Planetary gear box are compact and light weight than the conventional gear box.

d) In design of planetary gear box, iterative considerations need to be given for composite arrangement to have minimum number of components, higher transmission efficiency, and higher load carrying capacity.

e) High reductions ratios are possible in single stage differential planetary gear arrangement but will work for low torque applications only like positioning systems in robotics, aerospace.

Based on these findings, the identified research gap is presented in next point.

\subsection{Identified Research GAP}

The research gap was identified from the findings of the literature review and was presented as below :

1. Very few researchers had reported the study on design of composite planetary trains. However high reduction ratio (78:1) was not designed in two stage planetary gear train.

2. High reduction in single stage differential planetary gears arrangement works only for low torque application and has low efficiency.

3. In conventional helical gear system, the ratio 78: 1 requires three stage reductions which become bulky.

Hence authors had identified problem as "Design of two stage planetary gear trains for reduction ratio 78: 1" and the objective of study are as under.

\subsection{Objective of Study}

In tune with the findings of literature review and the identified problem, the objectives of the proposed research work are as under:

1) To design a two stage planetary gear train for reduction ratio $78: 1$.

2) To compare the strength, Size, weight and torque densities of this planetary gear train with equivalent existing designed helical gear train.

In order to achieve the above objective, methodology of design used is explained in next point.

\section{METHODOLOGY OF DESIGN}

The design of planetary gear trains consists of following steps:

a) Determination of reduction ratio for each stage. b) Calculation of number teeth of sun, planets and ring gear.

c) Material and heat treatment Selection.

d) Calculation of contact and bending stress of Gears.

e) Calculation of safety Factors in Hertizen contact stress and bending stress.

\subsection{Determination of Reduction Ratio for each} Stage

The reduction ratio for the given composite arrangement is product of ratios of each stage.

Total reduction ratio, $\mathrm{R}=\mathrm{R} 1 \bullet \mathrm{R} 2 \bullet \mathrm{R} 3 \bullet \ldots . . \mathrm{Rn} \ldots$ (1)

Where, R1, R2, R3, ...Rn represents the reduction ratios of each stage of gear train connected in composite.

For easier computation it is preferred that the planetary gear ratio shall be an exact integer $(3,4,6 \ldots)$. As a general practice, ratios used are in decimal system, a ratio of 10:1 is used even though this has no practical advantage for the computer/servo/motion controller. Actually, 10:1 or higher ratios are the weakest; while using the least "balanced" size gears and hence has the lower torque rating. Figure 3 illustrates a cross- section of such a planetary gear arrangement with its central sun gear, multiple planets (3), and the ring gear.

The reduction ratio in planetary gear train is determined as below:-

Ratio $=$ PCD of Ring Gear + PCD of Sun Gear
PCD of Sun Gear
Ratio $=\frac{\text { z1 }+ \text { z3 }}{\mathrm{z} 1}$

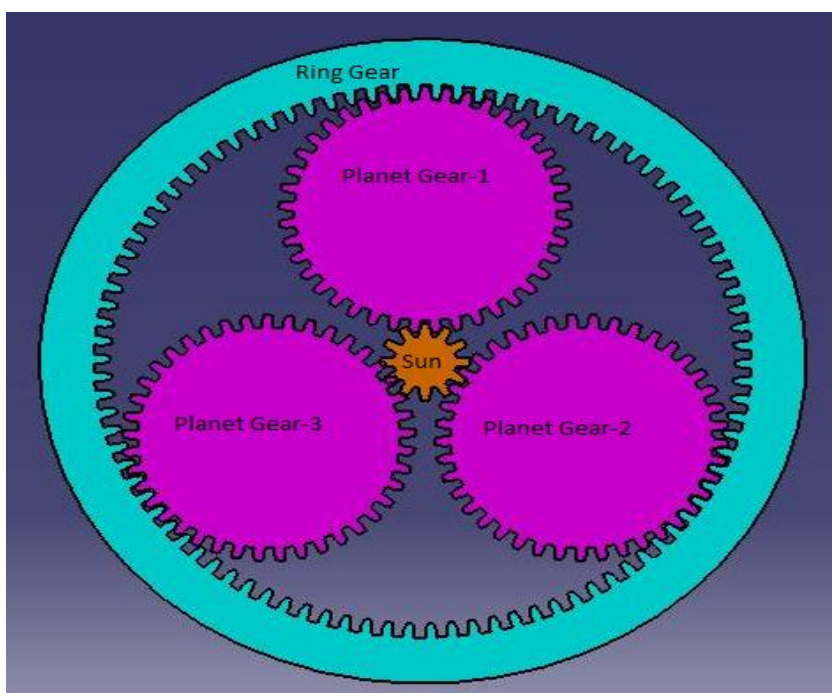

Fig- 3: Simple planetary gear

Where, $z 1=$ Number of teeth on Sun Gear. Z3 = Number of teeth on Ring Gear. 
A ratio 2:1 is not possible in a simple planetary gear system, since to satisfy the above equation for a ratio of $2: 1$ the sun gear would need to have the same diameter as the ring gear. Figure 4 shows the sun gear size for different ratios. With increased ratio, the sun gear diameter (size) is decreasing. Since gear size effects load ability, the ratio is a strong and direct influence factor for the torque rating.
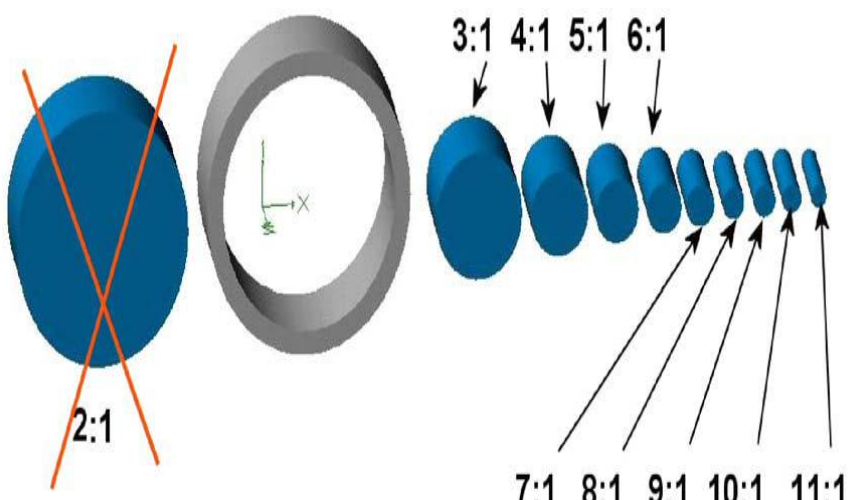

7:1 $8: 1 \quad 9: 1 \quad$ 10:1 $11: 1$

Fig- 4: Sun gear size for different ratios [11]

Figure 5 below shows the gears in a 3:1, 4:1, and 10:1 simple system. At $3: 1$ ratio, the sun gear is large and the planets are small. The planets are becoming "thin walled" thus limiting the space for the planet bearings and carrier pins, hence limiting the load ability. The $4: 1$ ratio is a well balance ratio, with sun and planets having the same size. 5:1 and 6:1 ratios still yield fairly good balanced gear sizes between planets and sun. With higher ratios approaching 10:1, the small sun gear becomes a strong limiting factor for the transferable torque. Simple planetary designs with 10:1 ratios have very small sun gears, which sharply limits torque rating.

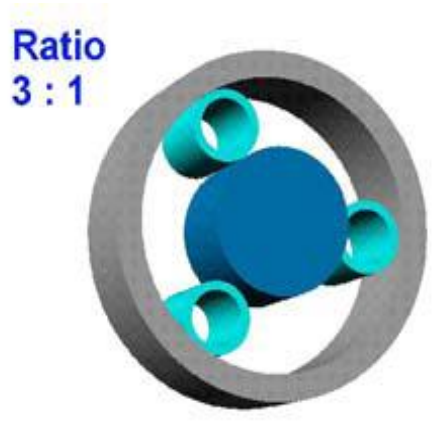

Ratio 3:1

Planets are smaller in size compared to sun

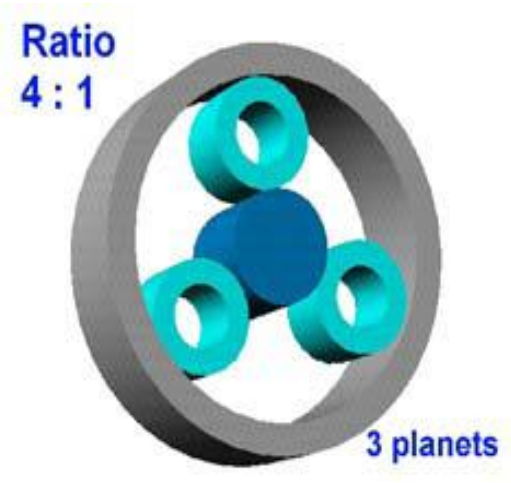

Ratio 4:1

Planets and sun gear are approximately equal in size

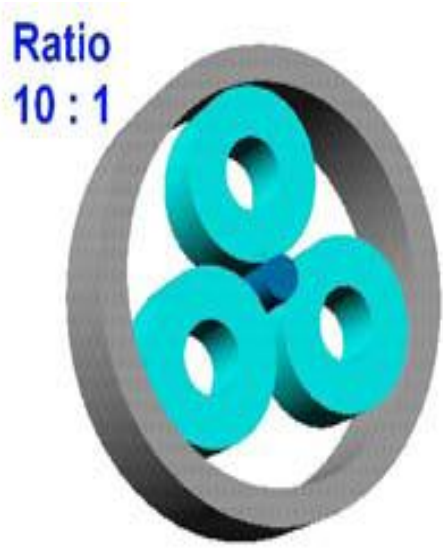

Ratio 10:1

Planets are big in size compared to sun

Fig- 5: Planetary gear ratios and the relationship between sun/planet size [12]

Increasing the number of planets, torque density on gear train will increase. But number planets will be decided by the reduction ratio. If reduction ratio is lower, higher number of planets can be used and in case of higher reduction ratios the planets will interfere with each other. If reduction ratio is greater than 10:1, multiple gears beyond say 3 planets would cause interference. This is illustrated in Figure 6.

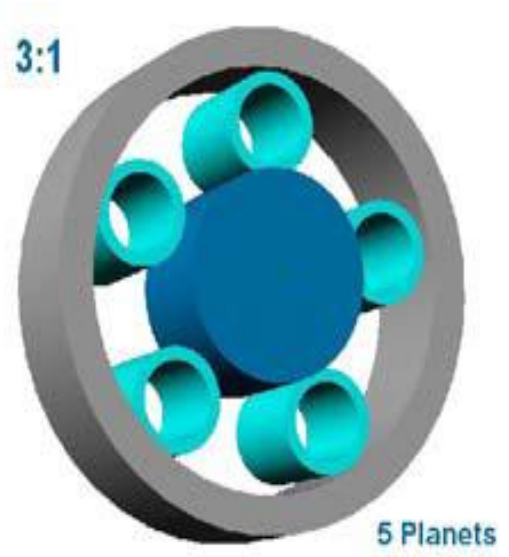

Ratio 3:1

Number of planets can be more than 5

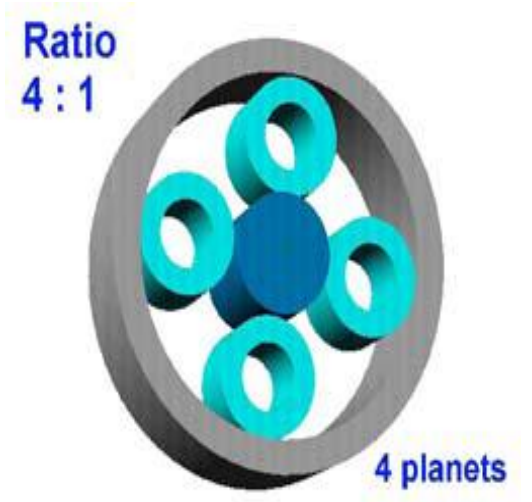

Ratio 4:1

Number of planets can be less than 5 


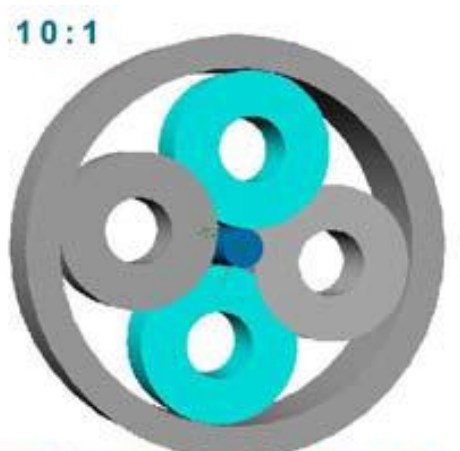

Ratio 10:1

Number of

planets can be

3 maximum

Interference / max. 3 palnets

Fig-6: 10:1 ratios should be avoided unless absolutely necessary from a technical point of view. If such ratios are used additional consideration must be given to arrangement/size vs. rating [12]

\subsection{Calculation of Number Teeth of Sun, Planets and Ring Gear}

Consider, Z1, Z2, Z3 are Number of teeth of Sun Gear, Planet Gear and Ring Gear.

Considering relation between Centre distance between sunplanet and planet- ring gear, we get

$$
\mathrm{Z} 3-\mathrm{Z} 1=2 \bullet \mathrm{Z} 2
$$

The number of teeth on sun and ring gear is determined by using equation (1) and teeth on planet gear are calculated by using equation (2)

\subsection{Material and Heat Treatment Selection}

The materials which are used for the gears depend upon the service factor and strength like wear or noise conditions etc, and they come in metallic and non-metallic form. For industrial purposes metallic gears are used, commercially can be obtained in steel, cast iron and bronze. Among these case hardening steel is widely used for industrial gears because of its excellent wearing properties and high bending strength, in which Case hardening steel $20 \mathrm{MnCr} 5$ as per DIN 17210 with tensile strength of $1200 \mathrm{MPa}$, was selected because low production cost, high stability and surface finish.

The heat treatment selected is case carburizing and hardening to high wear resistance for long service life. The hardness of 56 to $63 \mathrm{HRC}$ is selected as per AGMA -6019.

\subsection{Calculation of Contact and Bending Stress}

Bending contact and bending stress are determined as per the IS 4460 .

Contact (Pitting) stress $\left(\sigma_{\mathrm{H}}\right)$ for pitting can be calculated as below:

$$
\begin{aligned}
& \sigma_{\mathrm{HO}}=\mathrm{Z}_{\mathrm{H}} \bullet \mathrm{Z}_{\mathrm{E}} \bullet \mathrm{Z}_{\varepsilon} \bullet \mathrm{Z}_{\beta} \bullet \sqrt{ } \mathrm{Ft} \bullet(\mathrm{u}+1) /(\mathrm{b} \bullet \mathrm{d} 1 \bullet \mathrm{u} \bullet \mathrm{n}) \\
& \sigma_{\mathrm{H}}=\sigma_{\mathrm{HO}} \bullet \sqrt{ }\left(\mathrm{K}_{\mathrm{A}} \bullet \mathrm{K}_{\mathrm{V}} \bullet \mathrm{K}_{\mathrm{H} \beta} \bullet \mathrm{K}_{\mathrm{H} \alpha}\right)
\end{aligned}
$$

Bending stress $\left(\sigma_{\mathrm{F}}\right)$ for bending strength can be calculated as below:

$$
\begin{aligned}
& \sigma_{\mathrm{FO}}=\mathrm{Y}_{\mathrm{Fa}} \bullet \mathrm{Y}_{\mathrm{K}} \bullet \mathrm{Y}_{\mathcal{\varepsilon}} \bullet \mathrm{Y}_{\beta} \bullet \mathrm{Ft} /(\mathrm{b} \bullet \mathrm{mn} \bullet \mathrm{n}) \\
& \sigma_{\mathrm{F}}=\sigma_{\mathrm{FO}} \bullet \mathrm{K}_{\mathrm{A}} \bullet \mathrm{K}_{\mathrm{V}} \bullet \mathrm{K}_{\mathrm{F} \beta} \bullet \mathrm{K}_{\mathrm{F} \alpha}
\end{aligned}
$$

\subsection{Calculation of Safety Factors in Hertizan}

\section{Contact Stress and Bending Stress}

Calculate the allowable Hertizan Contact (Pitting) stress ( $\left.\sigma_{\mathrm{HP}}\right)$ on the material as below:

$$
\sigma_{\mathrm{HP}}=\sigma_{\mathrm{Hlim}} \bullet \mathrm{Z}_{\mathrm{L}} \bullet \mathrm{Z}_{\mathrm{l}} \bullet \mathrm{Z}_{\mathrm{R}} \bullet \mathrm{Z}_{\mathrm{S}} \bullet \mathrm{Z}_{\mathrm{V}} \bullet \mathrm{Z}_{\mathrm{W}} \bullet \sqrt{ } \mathrm{K}_{\mathrm{R}}
$$

Then calculate the safety factor in Contact stress $\left(\mathrm{S}_{\mathrm{H}}\right)$,

$$
\mathrm{S}_{\mathrm{H}}=\sigma_{\mathrm{HP}} / \sigma_{\mathrm{HO}}
$$

Calculate the allowable bending stress $\left(\sigma_{\mathrm{FP}}\right)$ on the material as below:

$$
\sigma_{\mathrm{FP}}=\sigma_{\mathrm{FE}} \bullet \mathrm{Y}_{\mathrm{N}} \bullet \mathrm{Y}_{\mathrm{n}} \bullet \mathrm{Y}_{\mathrm{R}} \bullet \mathrm{Y}_{\mathrm{S}} / \sqrt{ } \mathrm{K}_{\mathrm{R}}
$$

Then calculate the safety factor in Bending stress $\left(\mathrm{S}_{\mathrm{F}}\right)$,

$$
S_{\mathrm{F}}=\sigma_{\mathrm{FP}} / \sigma_{\mathrm{F}}
$$

Once the safety factors both in Hertizan contact and Bending are acceptable, the design is acceptable otherwise start from the first step by varying the reduction ratio on the gear train.

\section{CASE STUDY}

Presently for the automation of car parking systems in multistory building like Malls, cinema theaters etc., helical gear motor of $1.5 \mathrm{KW}$ input power, $1410 \mathrm{rpm}$ as input, 18 output rpm with safety factor as 1.0 is used. The gear boxes for these applications shall be compact, should have high torque density, shall be lubricated for life and operation shall be noiseless. But this is not possible in helical gear systems. Hence the design of planetary gear train for this application was done and the detailed calculations are as below:

$$
\begin{gathered}
\text { R }=\frac{\text { Input RPM }}{\text { Output RPM }} \\
\mathrm{R}=\frac{1410}{18}=78.33
\end{gathered}
$$

Total Reduction ratio $\mathrm{R}=78.33$, can be split into ratios $\mathrm{R} 1$ \& R2, where, R1 = Reduction ratio for first stage \&

$\mathrm{R} 2=$ Reduction ratio for second stage

Then, total reduction ratio $\mathrm{R}=\mathrm{R} 1 \bullet \mathrm{R} 2$ 
Let, $\mathrm{R}_{1}=\mathrm{R}_{2}$, then $\mathrm{R}=\mathrm{R}_{1}{ }^{2}$

Hence, $\mathrm{R}_{1}{ }^{2}=78.33$, Therefore $\mathrm{R}_{1}=8.85$,

Assume, $\mathrm{Z} 1=13, \quad$ we get $\mathrm{Z3}=103, \quad \mathrm{Z} 2=45$, final reduction ratio, $\mathrm{R}_{1}=8.923$

And $\mathrm{Z} 4=13$, we get $\mathrm{Z} 6=103, \mathrm{Z} 5=45$, final reduction ratio, $\mathrm{R}_{2}=8.923$.

Material selected for Gear was 20MnCr5 as per DIN 17210. The table: 1 shows the results of design calculations of existing helical gear system :

\begin{tabular}{|c|c|c|c|c|c|c|c|}
\hline \multicolumn{8}{|c|}{ Table No: 1 Existing Design of helical gear system } \\
\hline \multicolumn{2}{|c|}{ Stage number } & \multicolumn{2}{|c|}{ Stage-1 } & \multicolumn{2}{|c|}{ Stage-2 } & \multicolumn{2}{|c|}{ Stage-3 } \\
\hline Parameter & & Pinion-1 & Gear -2 & Pinion-3 & Gear -4 & Pinion-5 & Gear -6 \\
\hline No. of teeth & Unit & 21 & 62 & 11 & 51 & 9 & $\mathbf{5 0}$ \\
\hline module & & 1.00 & 1.00 & 2.25 & 2.25 & 3.50 & 3.50 \\
\hline PCD & & 23.28 & 68.72 & 26 & 118.45 & 36.00 & 200.00 \\
\hline OD & $\mathrm{mm}$ & 26.28 & 69.72 & 32 & 120.70 & 46.50 & 203.50 \\
\hline Root Diameter & $\mathrm{mm}$ & 21.78 & 65.22 & 65 & 110.58 & 30.75 & 187.75 \\
\hline Centre Distance & $\mathrm{mm}$ & 46 & 46 & 72 & 72 & 118 & 118 \\
\hline Material & & \multicolumn{6}{|c|}{$20 \mathrm{MnCr} 5$} \\
\hline Heat Treatment & & \multicolumn{6}{|c|}{ Case Carburizing } \\
\hline Hardness & HRC & 60 & 57 & 60 & 57 & 60 & 57 \\
\hline Contact Stress in Gear & $\mathrm{N} / \mathrm{mm}^{2}$ & 1359.56 & 1047.61 & 1503 & 1.78 & 1462.83 & 665.27 \\
\hline Bending stress in Gear & $\mathrm{N} / \mathrm{mm}^{2}$ & 545.26 & 866.02 & 305 & 466.93 & 90.64 & 365.13 \\
\hline Factor Safety in Pitting & & 1.07 & 1.42 & 1.00 & 1.80 & 1.02 & 2.26 \\
\hline Factor Safety in Bending & & 1.51 & 1.00 & 2.72 & 1.78 & 8.84 & 2.28 \\
\hline \begin{tabular}{|l|} 
Volume \\
\end{tabular} & $\mathrm{mm}^{3}$ & 0.0045 & 0.0247 & 0.0135 & 0.2356 & 0.0478 & 1.3196 \\
\hline Weight & $\mathbf{N}$ & 0.349 & 1.900 & 1.041 & 18.141 & 3.685 & 101.623 \\
\hline
\end{tabular}

Table: 2 shows the results of design calculations of new planetary gear system

\begin{tabular}{|c|c|c|c|c|c|c|c|}
\hline \multicolumn{8}{|c|}{ Table No: 2 Design of two stage planetary gear system } \\
\hline \multirow[b]{2}{*}{ Parameter } & \multirow[b]{2}{*}{ Unit } & \multicolumn{3}{|c|}{ Stage $: 1$} & \multicolumn{3}{|c|}{ Stage : 2} \\
\hline & & $\begin{array}{c}\text { Sun Gear } \\
-1\end{array}$ & $\begin{array}{l}\text { Planet Gear } \\
-2\end{array}$ & \begin{tabular}{|l} 
Ring Gear \\
-3
\end{tabular} & Sun Gear & Planet Gear & Ring Gea \\
\hline No. of teeth & & 13 & 45 & 103 & 13 & 45 & 103 \\
\hline \begin{tabular}{|l|} 
module \\
\end{tabular} & & 1.25 & 1.25 & 1.25 & 2.25 & 2.25 & 2.25 \\
\hline PCD & $\mathrm{mm}$ & 16.25 & 56.25 & 128.75 & 29.25 & 101.25 & 231.75 \\
\hline OD & $\mathrm{mm}$ & 18.13 & 58.75 & 125.625 & 32.63 & 105.75 & 226.13 \\
\hline Root Diameter & $\mathrm{mm}$ & 12.73 & 53.13 & 131.875 & 22.92 & 95.63 & 237.38 \\
\hline Centre Distance & $\mathrm{mm}$ & 36.25 & 36.25 & 36.25 & 65.25 & 65.25 & 65.25 \\
\hline No of planets & & & 2 & & & 3 & \\
\hline Material & & \multicolumn{6}{|c|}{$20 \mathrm{MnCr} 5$} \\
\hline Heat Treatment & & \multicolumn{6}{|c|}{ Case Carburizing } \\
\hline Hardness & HRC & 60 & 57 & 55 & 60 & 57 & 55 \\
\hline Contact Stress in Gear & $\mathrm{N} / \mathrm{mm}^{2}$ & 1441.03 & 761.78 & 522.73 & 1455.61 & 1211.56 & 765.40 \\
\hline Bending stress in Gear & $\mathrm{N} / \mathrm{mm}^{2}$ & 294.26 & 205.14 & 415.14 & 299.93 & 650.65 & 434.90 \\
\hline Factor Safety in Pitting & & 1.01 & 1.95 & 2.88 & 1.00 & 1.23 & 1.96 \\
\hline Factor Safety in Bending & & 2.85 & 4.10 & 1.98 & 2.79 & 1.29 & 1.89 \\
\hline Volume & $\mathrm{mm}^{3}$ & 0.0039 & 0.0404 & 0.1270 & 0.0227 & 0.2516 & 0.3925 \\
\hline Weight & $\mathrm{N}$ & 0.299 & 3.110 & 9.782 & 1.747 & 19.379 & 30.225 \\
\hline
\end{tabular}

The results obtained are compared on the technical parameters and discussed in details in next paragraph.

\section{RESULTS AND DISCUSSION}

The results obtained above are compared on the basis of Size (Volume), weight, and torque density. The detailed are discussed as below: i) The comparison of volumes of gears in planetary and helical was done and presented in graph-1. Gears were represented by numbers $1,2,3,4,5,6$ on $\mathrm{x}$ - axis. In case helical gear system the volume drastically increases as torque increase, whereas this increase was uniform in case of planetary gear system. This increase was very high in last stage gear which transmits the full torque of the transmission system.

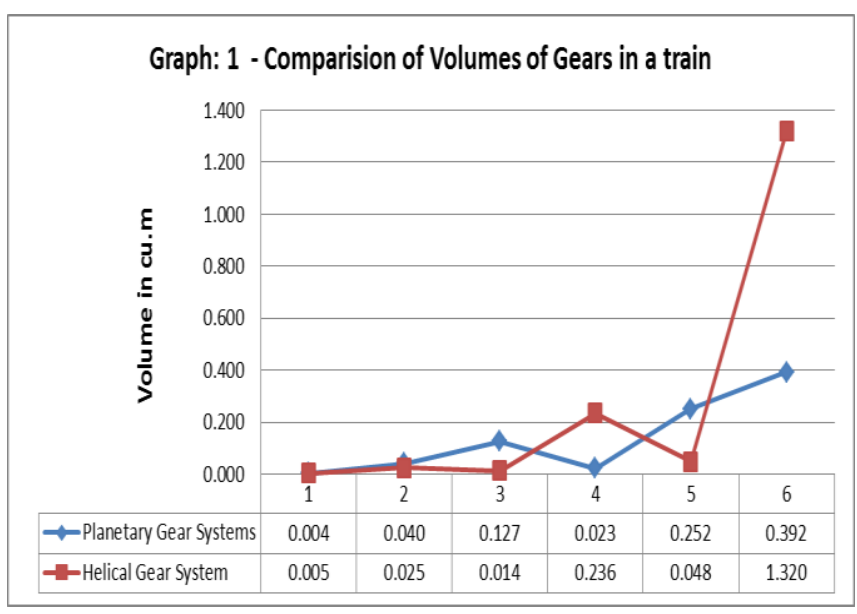

ii) The comparison between weights of gears in planetary and helical gear systems was done and presented in graph-2. Gears were represented by numbers $1,2,3,4,5,6$ on $\mathrm{x}$ - axis. In case helical gear system the weight drastically increases for final stage gear which transmits the full torque of the transmission system.

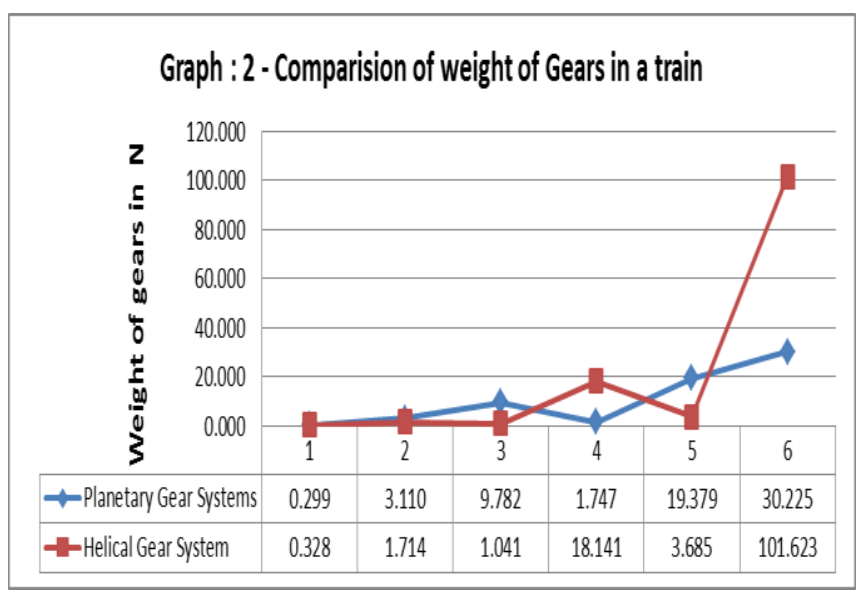

iii) The torque density for planetary gear system and helical gear system was compared and the results are tabulated in table-3 \& 4 below:

Table -3: Comparison of Size and Weight

\begin{tabular}{|l|l|l|l|}
\hline $\begin{array}{l}\text { S.N } \\
\text { o. }\end{array}$ & Description & $\begin{array}{l}\text { Volume } \\
(\text { cu. m) }\end{array}$ & $\begin{array}{l}\text { Weight } \\
(\mathrm{N})\end{array}$ \\
\hline 1 & Planetary Gears & 0.838 & 64.542 \\
\hline 2 & Helical Gears & 1.643 & 126.740 \\
\hline 3 & Reduction in \% & 49 & 49 \\
\hline
\end{tabular}


Table -4: Comparison of Torque Density

\begin{tabular}{|l|l|l|l|}
\hline $\begin{array}{l}\text { S. } \\
\text { No. }\end{array}$ & Description & $\begin{array}{l}\text { Torque/Volume } \\
(\mathrm{N}-\mathrm{m} / \mathrm{cu} . \mathrm{m})\end{array}$ & $\begin{array}{l}\text { Torque/Weig } \\
\mathrm{ht} \\
(\mathrm{N}-\mathrm{m} / \mathrm{N})\end{array}$ \\
\hline 1 & Planetary Gears & 950.027 & 12.34 \\
\hline 2 & Helical Gears & 484.595 & 6.28 \\
\hline 3 & Increase in $\%$ & $96 \%$ & $96 \%$ \\
\hline
\end{tabular}

From the above table, torque density (both Torque/volume \& torque/weight) was $96 \%$ high for planetary gear systems as compared to helical gear system. Planetary gear system was $49 \%$ compact in Volume and weight both than equivalent helical gear system.

iv) Graph-3 \& 4 represents the Factor of safety in Pitting and Bending plotted for the comparision of variation in strength throgh the power transmission from gear 1 to 6 .
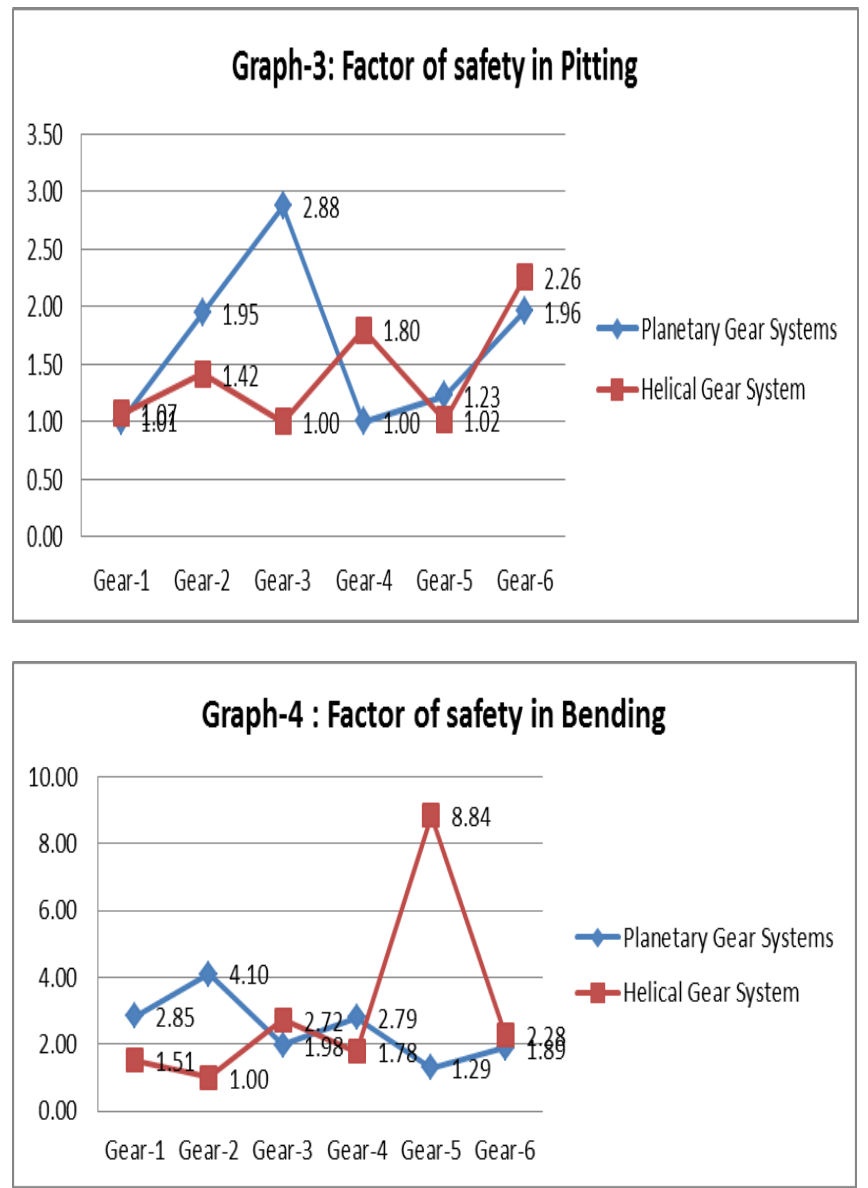

\section{CONCLUSION}

Above study \& results enables us to draw the following conclusion:

1) Reduction ratio 78:1 is achieved in 2 stages for planetary gears which was in 3 stage with helical gears, Hence planetary gear system becomes compact as one stages is eliminated.

2) Planetary gears have uniform strength (factor safety) in bending against equivalent helical gears.
3) The volume of planetary gear system for the given torque was $49 \%$ less than equivalent helical gear system.

4) The weight of planetary gear system for the given torque was $49 \%$ less than equivalent helical gear system.

5) The torque density (Torque/volume or Torque/ weight) of planetary gear system for the given torque was $96 \%$ higher than equivalent helical gear system.

\section{ACKNOWLEDGEMENTS}

Thanks are expressed to the M/s LAXMI HYDRAULICS PVT.LTD, SOLAPUR for allowing to study on this subject and their full hearted co-operation in providing all the necessary data and detailed guidance during this work.

\section{REFERENCES}

[1]. Lehao Chang, Geng Liu, Liyan WuDr, "A robust model for determining the mesh stiffness of cylindrical gears" Mechanism and Machine Theory 87 (March-2015) PP: 93114

[2]. Dr. Alexander Kapelevich "High Gear Ratio Epicyclic Drives Analysis" GEAR TECHNOLOGY, June 2014 PP: 61-67

[3]. Ovidiu Buiga, Lucian Tudose "Optimal mass minimization design of a two-stage coaxial helical speed reducer with Genetic Algorithms" Advances in Engineering Software 68 (2014) PP: 25-32

[4]. Bernd-Robert Höhn, Karsten Stahl and Philipp Gwinner "Light-Weight Design for Planetary Gear Transmissions" GEAR TECHNOLOGY, Sept. 2013, PP: 96-103

[5]. Syed Ibrahim Dilawer, Md. Abdul Raheem Junaidi, Dr.S.Nawazish Mehdi "Design, Load Analysis and Optimization of Compound Epicyclic Gear Trains" American Journal of Engineering Research ISSN 2320-0936 Vol.-02, Issue-10, 2013, PP: 146-153

[6]. Cheon-Jae Bahk, Robert G. Parker "Analytical investigation of tooth profile modification effects on planetary gear dynamics" Mechanism and Machine Theory 70 (2013) PP: 298-319

[7]. Nenad Marjanovic, Biserka Isailovic, Vesna Marjanovic, Zoran Milojevic, Mirko Blagojevic, Milorad Bojic, "A practical approach to the optimization of gear trains with spur gears" Mechanism and Machine Theory 53 (2012) PP:1-16

[8]. Jelena Stefanović-Marinović and Miloš Milovančević "Load Allocation and Equilibrium for Planetary Gear Reducers of Earth-Pressure-Balance Shield Machine" Journal of Mechanics Engineering and Automation 2 (2012) PP: 365-373

[9]. Ulrich Kissling, Inho Bae, “Optimization Procedure for Complete Planetary Gearboxes with Torque, Weight, Costs and Dimensional Restrictions" Applied Mechanics and Materials Vol. 86 (2011) pp 51-54.

[10]. Dr.-Ing. T. Schulze, Dipl.-Ing. C. Hartmann, Prof. Dr.Ing. B. Schlecht, "Calculation of Load Distribution in Planetary Gears for an Effective Gear Design Process" American Gear Manufacturers Association October 2010 ISBN: 978--1--55589--983-7 10FTM08 PP: 1-11 
[11]. B. Venkatesh, V. Kamala, \& Me. A.M. K. Prasad "Design, modeling \& manufacturing of Helical Gear" International Journal of applied Engineering Research Dingidul, Vol-1 2010, PP-103-114

[12]. Gerhard G. Antony, Neugart and Arthur Pantelides, "Precision Planetary Servo Gearheads" American Gear Manufacturers Association October, 2006, 06FTM04 PP: 113

[13]. IS 4460: Calculation of Load Capacity: Spur and Helical Gears.

[14]. AGMA 6019 E89: Standard for Gear motors using Spur, Helical, Herringbone, Straight bevel or Spiral bevel gears.

\section{BIOGRAPHIES}

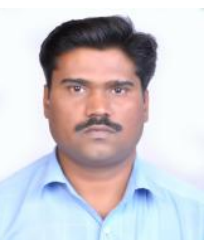

Prabhakar Vitthal Pawar, completed a bachelor degree in Production Engg. in 1999. Joined a small scale gear motor manufacturing unit LHP as a trainee Engineer. Worked as a Gear Box Design Manager for 5 years. Now pursuing Master of Engineering in Mechanical Design from Solapur University under guidance of Prof. P. R. Kulkarni.

Prabhakar.vpawar@gmail.com

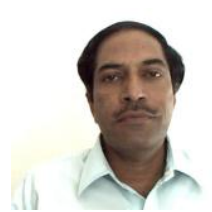

P.R. Kulkarni, Professor, Area of Specializations: Mechanical Engg, Heat Power Engg, Industrial Engg, Mechanical Engineering Dept. Walchand Institute of Technology, Solapur-413003, pradip.pr@gmail.com 